\title{
A Novel Method for Microstructural Characterization of Cast Iron
}

\section{J P Aral Mozhi Varman}

M. S. Research Scholar, Department of Metallurgical and Materials Engineering, Indian Institute of Technology - Madras, Chennai - 600 036, India

The difficulty in the metallography of gray cast iron lies in the differentiation of ferrite and iron phosphide eutectic (steadite) microconstituents by using normal etchant like nital, picral and both these phases appears as bright under normal light microscope. Hence, it is difficult to find out the relative amounts of phases, either photo micrographically or using sophisticated image analysis software. In general industry practice, the samples are etched with $2 \%$ to $3 \%$ nital for quantification of ferrite, steadite and cementite plus carbide particles under optical (light) microscope. This method of inspection requires high skill to differentiate the ferrite and iron-phosphide eutectic (steadite) microconstituents and also sometimes it leads to misinterpretation. This led to the development of a novel etching method called Selenic etchant, in which the steadite and ferrite constituents are differentiated at $100 \%$ confidence level and the precise quantification of phases were done.

\section{References}

[1] J.M. Radzikowska, ASM Handbook, "Metallography and Microstructures", ASM International, Materials Park, Ohio, USA, Vol. 9 (2004), p. 580-586.

[2] Edward Fras et al, "Solidification conditions of Gray and White cast iron, Part II - Experimental verification", Metallurgy and Foundry Engineering, Vol. 31 (2005), p.43.

[3] K. Sandau, "Characterization of Microstructures using the Chord Length Transformation", Microscopy and Microanalysis, Vol 2. (2005), p. 1624-1625.

[4] The authors acknowledge funding from the WABCO-TVS India Ltd for their many useful discussions and contributions to this work. 


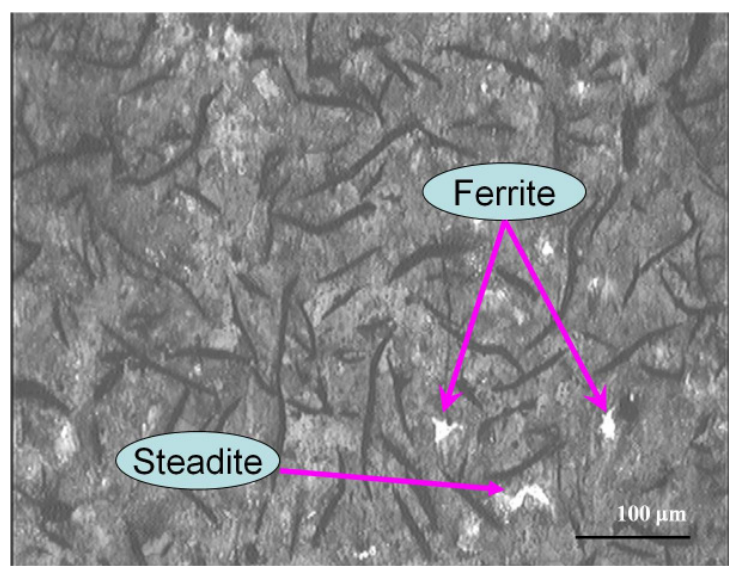

Figure 1. Microstructure of cast iron etched with normal etchants such as nital and picral, which reveals both the ferrite and steadite microconstituents appears as white color under optical microscope

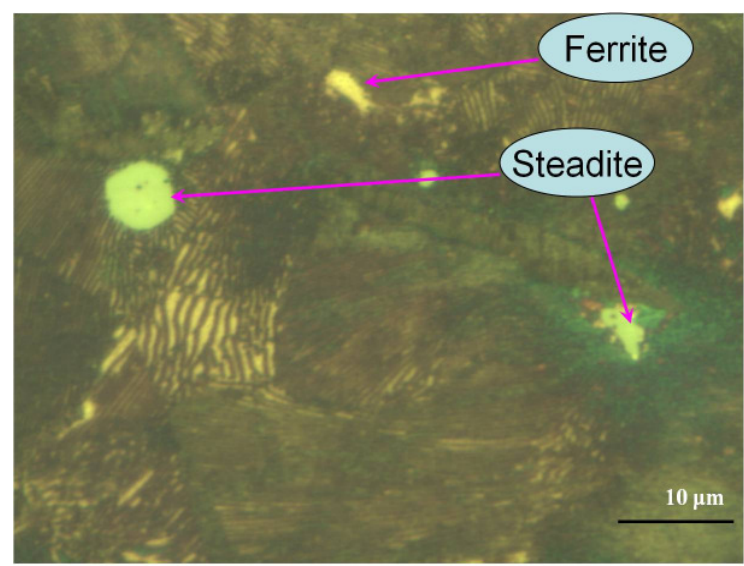

Figure 2. Microstructure of cast iron etched with selenic etchant, which differentiates the ferrite and steadite microconstituents as yellow and green colour respectively 